\title{
Support the volunteer doctors helping the world's refugees
}

The charity Doctors of the World is well versed in bringing care to the most vulnerable people in both developing and developed countries, which is why we've chosen it for The BMJs Christmas appeal this year, writes Jane Feinmann. Please give generously

\section{Jane Feinmann freelance journalist, London, UK}

It's all too easy to feel helpless about the ongoing plight of the refugees crossing Europe during 2015. In the most recent development thousands of men, women, and children are stranded near the town of Idomeni, on the border of Greece and Macedonia.

The charity Doctors of the World aims to meet the serious medical and emotional health needs of all excluded people and is working in almost every country affected to provide support for refugees. It is part of the global Médecins du Monde network, which delivers more than 350 projects in more than 80 countries through 3000 volunteers. The organisation relies on donations to do this work.

"We already have volunteer doctors in Idomeni offering basic healthcare checks and treatment to the thousands of refugees who have been crossing the border here every day for several months," explained Gareth Walker, international programme manager of Doctors of the World.

\section{Urgently seeking donations}

Now the charity is urgently seeking donations to send out volunteer doctors to offer healthcare to the growing population of refugees who are stuck because Macedonia has closed its border to refugees from countries other than Syria, Iraq, or Afghanistan who are making their way west.

The charity's response to "a level of population movement not seen since the second world war," as Walker describes it, varies by country.

In Greece, Slovenia, and Croatia, the charity's healthcare provision includes volunteer doctors and nurses as well as salaried local doctors and nurses providing immediate primary healthcare as well as referring urgent cases to local hospitals. Further west, the charity works with local health authorities, other charities, and non-governmental organisations to provide services for refugees. It also holds governments to account to ensure they fulfil their responsibility to provide basic healthcare and services for refugees.
"Right across Europe today refugees, including pregnant women and very young children, are living in appalling conditions lacking essentials such as safe drinking water, adequate food, sanitation, and proper shelter as well as access to basic healthcare," says Walker. "That level of need requires action at government level."

In Calais, for instance, the charity helps fund a clinic staffed by volunteer general practitioners that provides healthcare to about 6000 refugees waiting to travel to the UK. In addition, the charity brought legal action to force the French state to provide fresh water, shelter, and sanitation for camp residents, a move upheld by the High Court in Paris at the end of November. "It was a huge amount of backroom work but worth it for the health benefits for these refugees," says Walker.

\section{Work in the UK}

The charity's work in the UK takes the same approach. It runs three clinics in Bethnal Green and Hackney in east London and in Brighton, with 30 volunteer GPs, 20 nurses, and 50 case workers providing social and medical consultations to people having difficulty accessing mainstream healthcare, along with recently established pop-up clinics at organisations working with refugees and migrants.

But the charity has also lobbied NHS England to clarify the rules on registration at general practices. "We are pleased that NHS England has just published guidance making it clear that there is no regulatory requirement for people, notably refugees, to have proof of address or the right identification to register with a GP," explained Lucy Jones, UK organiser of the charity. The charity also runs a family clinic twice a month for pregnant women and children. "We see women who are 38 weeks pregnant who have not even had a scan," says Jones. "Providing this service should not rely on donations in a country such as England. But the fact is we urgently need funding to enable us to do this essential work." 


\section{Donate to Doctors of the World}

- $£ 80$ could provide 10 psychological consultations for survivors of war

- $£ 135$ could provide an emergency backpack containing drugs and consumables used by mobile doctors to treat refugees in Greece and the Balkans

- $£ 180$ could provide 25 hygiene kits for refugees living in poor sanitary conditions throughout Europe

- Donate online: www.doctorsoftheworld.org.uk/BMJ

- Donate $£ 10$ by text message: text DOCTOR to 70660 (UK mobiles only)

- Donate by phone: $+44(0) 2035357955$ 